OPEN ACCESS

Edited by:

Qiaobao Zhang,

Xiamen University, China

Reviewed by:

Chundong Wang,

Huazhong University of Science and

Technology, China

Juchen Guo,

University of California, Riverside,

United States

Shuge Dai,

Zhengzhou University, China

*Correspondence:

Chaoyang Wang

wangchy807@caep.cn

Yongjian Tang

tangyongjian2000@sina.com

Specialty section:

This article was submitted to Nanoscience,

a section of the journal

Frontiers in Chemistry

Received: 27 July 2018 Accepted: 20 September 2018 Published: 17 October 2018

Citation:

Liu X, Mi R, Yuan L, Yang F, Fu Z,

Wang $C$ and Tang $Y$ (2018)

Nitrogen-Doped Multi-Scale Porous

Carbon for High Voltage Aqueous

Supercapacitors. Front. Chem. 6:475.

doi: 10.3389/fchem.2018.00475

\section{Nitrogen-Doped Multi-Scale Porous Carbon for High Voltage Aqueous Supercapacitors}

\author{
Xichuan Liu ${ }^{1,2}$, Rui $\mathrm{Mi}^{2}$, Lei Yuan ${ }^{2}$, Fan Yang ${ }^{2}$, Zhibing Fu ${ }^{2}$, Chaoyang Wang ${ }^{2 *}$ and \\ Yongjian Tang ${ }^{1,2 *}$
}

'Shanghai EBIT Lab, Key Laboratory of Nuclear Physics and Ion-beam Application, Department of Nuclear Science and Technology, Institute of Modern Physics, Fudan University, Shanghai, China, ${ }^{2}$ Science and Technology on Plasma Physics Laboratory, Research Centre of Laser Fusion, China Academy of Engineering Physics, Mianyang, China

Recently, "Water-in-salt" electrolyte has been reported to extend the working voltage of aqueous supercapacitor. However, this electrolyte needs the electrode materials possess some good features such as proper pore structure, high electron and ion conductivity. Herein, we fabricated the nitrogen-doped multi-scale porous carbon (NMC) by the simple enriching melamine-resorcinol-formaldehyde xerogels method with integrating triblock copolymer for micro-pores formation. All the results confirmed that our NMC is provided with a very high specific surface area $\left(3,170 \mathrm{~m}^{2} \mathrm{~g}^{-1}\right)$ and its monoliths are composed of multi-scale porous structure. By employing the nanostructured NMC as electrode materials, we have investigated the capability for high-voltage aqueous supercapacitor applications. The superconcentrated "Water-in-salt" electrolyte expand stability operating potential window of aqueous symmetric supercapacitor up to $2.4 \mathrm{~V}$ with a high energy density of $33 \mathrm{Wh} \mathrm{kg}^{-1}$ at power density of $0.3 \mathrm{~kW} \mathrm{~kg}^{-1}$. Our studies indicate that the $\mathrm{NMC}$ is potential materials for high performance over wider voltage range.

Keywords: supercapacitors, aqueous electrolyte, water in salt, porous carbon, high voltage, energy density

\section{INTRODUCTION}

For the fast consumption of fossil fuels leads to global severe environmental issues and energy crisis, exploitation of new energy sources become an urgent issue for humanity. For decades, many works have been devoted to develop new technologies to use new energy sources from the ambient or renewable sources like wind, solar, tide, electromagnetic fields, mechanical movement and so on, and converted to electrical energy in an energy storage device like batteries (Zhao et al., 2017; Zhang et al., 2018a). However, due to the intermittent nature of these energy sources, batteries will be charged repeatedly which resulted in rapid decay of their cycle life. In this case, supercapacitors (SCs) with favorable features of long cycling stability, fast charging/discharging ability and high power density are generally more suitable than batteries (Jia et al., 2018; Liu et al., 2018b; Qu et al., 2018). Specifically, since the SCs have high specific power characteristic, it also have been widely used in a wide variety of applications such as portable electronics, electric or hybrid electric vehicles, aircraft and smart grids.

Nevertheless, the low energy densities of SCs restrict its widespread applications. According to the Equation (1), the energy density (E) is related to the capacitance (C) and operating voltage (V). For increasing the energy stored in SCs, previous works have been widely focused on the improvement of capacitance which takes advantage of various topical subjects like the selection, the 
construction, and the modification of electrode materials (Zhong et al., 2015; Dai et al., 2017; Liu et al., 2018a). So far, few researches focus on the crucial factors correlating to the operating voltage, even though it is more efficient to increase the energy density and power density $(\mathrm{P})$, according to the Equation (2) (where R is the internal resistance) by expanding the operating voltage, since energy density and power density are directly proportional to the square of voltage.

$$
\begin{aligned}
& E=C V^{2} / 2 \\
& P=V^{2} / 4 R
\end{aligned}
$$

The SCs are usually use three types electrolyte (Zhong et al., 2015): aqueous, organic and ionic liquid (Kühnel and Balducci, 2014). Using organic or ionic liquid electrolyte can efficiently expand the potential window, which because of the organic or ionic liquid electrolyte has a good electrochemical stability with higher decomposition voltage $(2.5-4.5 \mathrm{~V})$ than aqueous. However, a series of undesired features severely limit the wide application of organic electrolyte. For example, the SCs with organic and ionic liquid electrolytes often suffer from low capacitances and power densities due to their large-size ion and low ionic conductivity nature. In addition, the organic and ionic liquid electrolytes are not only noxious and flammable result in environmental and security issues, but also require rigorous manufacturing procedures. On the contrary, aqueous electrolytes get more attention due to its inherently safety, low-cost, and easy operation characters. For the smaller-size ion and faster ionic conductivity enable aqueous SCs with larger capacitances and higher power densities (Zao et al., 2016; Hwang et al., 2017; Zeng et al., 2018a). So, it is urgent to study aqueous SCs with both high energy and power density fulfilling the application of the SCs.

The most challenge to obtain high-voltage aqueous SCs is expanding the electrochemical stability window of water $(1.23 \mathrm{~V})$, previous studies have devoted to asymmetry structure or neutral aqueous electrolytes, and the highest potential window even beyond 2 V (Yang et al., 2017; Zuo et al., 2017; Fu et al., 2018). Very recently, Yu et al. (2017) summarized the new insight into the high voltage of aqueous SCs. Many crucial tactics of expanding the operating voltage have been studied. Specifically, Xu et al. (Suo et al., 2015) reported an intriguing breakthrough that a superconcentrated lithium bis(trifluoromethane sulfonyl)imide (LiTFSI) aqueous solution named "water-in-salt" electrolyte displays a obviously high electrochemical stability up to $3 \mathrm{~V}$ in lithium-ion batteries applications. Obviously, this "water-in-salt" electrolyte also can be used in high voltage aqueous SCs (Gambou-Bosca and Bélanger, 2016; Díez et al., 2017; Reber et al., 2017). For instance, Hasegawa, et al. (Zhao et al., 2016) fabricates symmetric SCs using $5 \mathrm{M}$ LiTFSI aqueous solution achieved a maximum stable operating voltage of $2.4 \mathrm{~V}$. Nevertheless, although using the LiTFSI aqueous solution expand the operating voltage of $\mathrm{SCs}$, it is also suffered the sacrifice of capacitances, which result in the limited increasing of energy density. Therefore, it is needed to choose one proper electrode materials for matching the LiTFSI molecule to maximization the capacitances as well as expanding the operating voltage. In this case, multi-scale carbonaceous materials with high good thermal and chemical stability, good porous network, and satisfactory electrical conductivity have been widely studied, and it is very suitable for SCs. (Huang et al., 2012; Fang et al., 2013; Hasegawa et al., 2016). Moreover, N-doped carbon materials have many attractive functional properties. It also gives more active sites for electrochemical reactions in double layer capacitors (Geng et al., 2011; Ci et al., 2012; Zhong et al., 2013; Zhang et al., 2018b). Furthermore, for the excellent performance of Ndoped carbon, it has been studied in long-term performance in SCs (Wen et al., 2012; Zhu et al., 2016; Zeng et al., 2018b).

In this work, Nitrogen-doped multi-scale carbon (NMC) was fabricated by simple sol-gel reaction with additional $\mathrm{CO}_{2}$ activation. The structure of this material is comprised of a multiscaled pore with nano-porous carbon in a network of micron-size percolated hollow-duct. In particular, the prepared NMC was utilized as electrode materials to explore high-voltage aqueous supercapacitors.

\section{EXPERIMENTAL}

\section{Materials Synthesis}

NMC were fabricated by sol-gel method from a solution containing resorcinol (R), formaldehyde (F) and melamine (M), followed by aging, solvent exchange, drying and pyrolysis. In a typical process, firstly, $1.6 \mathrm{~g}$ of triblock copolymer Pluronic F68 $\left(\mathrm{PEO}_{76}-\mathrm{PPO}_{29}-\mathrm{PEO}_{76}\right)$ was dissolved in a small amount of deionized water and ethanol at $60^{\circ} \mathrm{C}$, followed by adding $7.7 \mathrm{~g}$ of melamine and $18 \mathrm{~mL}$ of formaldehyde solution (37 wt \%), with vigorous stirring until melamine was completely dissolved. Then, $6.5 \mathrm{~g}$ of resorcinol and $8.7 \mathrm{~mL}$ of formaldehyde solution were added into the above mixture solution, and stirring until resorcinol was completely dissolved. After that, $6 \mathrm{~mL}$ of $\mathrm{NaOH}$ solution $(0.02 \mathrm{M})$ was added into the above mixture using as catalyst. At last, amount of deinoized water was added to meet the volume at $50 \mathrm{~mL}$. The mixture was stirred at $60^{\circ} \mathrm{C}$ for $3 \mathrm{~min}$. Hereafter, the mixture was placed in a sealed container and kept at $60^{\circ} \mathrm{C}$ for $72 \mathrm{~h}$ to finish the gel process. The M-R$\mathrm{F}$ hydrogels containing $\mathrm{PEO}_{76}-\mathrm{PPO}_{29}-\mathrm{PEO}_{76}$ were immersed in a solution of trifluoroacetic acid and ethanol (3:97 in volume) at room temperature for $72 \mathrm{~h}$. Afterwards, the residual solvent was substitute for ethanol for 6 times per $24 \mathrm{~h}$ to remove water. Subsequently, the hydrogels were dried at $60^{\circ} \mathrm{C}$ and carbonized with argon gas flow rate of $100 \mathrm{~mL} \mathrm{~min}{ }^{-1}$ at $800^{\circ} \mathrm{C}$ for $4 \mathrm{~h}$. And this nitrogen-containing porous carbon without $\mathrm{CO}_{2}$ activation was denoted as NC. In the $\mathrm{CO}_{2}$ activation process, the NC was heated in a tubular furnace at $950^{\circ} \mathrm{Cfor} 8 \mathrm{~h}$ under a stable $\mathrm{CO}_{2}$ flow $\left(150 \mathrm{~mL} \mathrm{~min}^{-1}\right)$ and then the NMC was obtained. For comparison, the commercialized active carbon YP-50 (AC) was purchased from Kuraray chemical co. (Japanese).

\section{Characterization of the Samples}

The morphology of the NC and NMC was observed by scanning electron microscopy (SEM) and high-resolution transmission 
electron microscopy (HRTEM). The crystallographical information and phase of the samples were investigated by X-ray powder diffraction (XRD) and Raman spectroscopy. $\mathrm{N}_{2}$ adsorption/desorption isotherms were tested by an AUTOSORB-IQ surface area analyzer (Quantachrome Instrument Corporation) at $77 \mathrm{~K}$. The chemical composition of the NMC was conducted with X-ray photoelectron spectroscopy (XPS).

\section{Electrochemical Measurements}

For electrochemical experiments, the working electrodes were fabricated with $80 \mathrm{wt} \%$ active materials, $10 \mathrm{wt} \%$ acetylene black and $10 \mathrm{wt} \%$ polytetrafluoroethylene (PTFE) in ethanol to form a mixture solution. And the mixture was pressed onto stainless steel network at $20 \mathrm{MPa}$ with a diameter of $16 \mathrm{~mm}$ and a mass of around $2 \mathrm{mg}$. The electrode was tested in two- and three-electrode cells. The $20 \mathrm{~mol} \mathrm{~kg}{ }^{-1}$ (m) LiTFSI aqueous solution was used as electrolytes. Two-electrode capacitor was tested in a CR2032-type coin cell with comparable mass of active materials, while a piece of sulfonated polypropylene membrane was employed as separator. In a three electrode cell, a pair of electrodes was used as working and counter electrode respectively, and the saturated calomel electrode (SCE) was used as reference electrode. The galvanostatic charge/discharge tests (GCD) and cycling performance were tested at LAND instrument (CT2001, China). Cyclic voltammetry (CV) was tested in the same range by a CHI 760 electrochemical workstation. Electrochemical impedance spectroscopy (EIS) measurements were performed from $100 \mathrm{kHz}$ to $10 \mathrm{mHz}$.

\section{RESULTS AND DISCUSSION}

\section{Morphologies and Crystallographical Information}

Studies on the R-F sol-gel reaction (Al-Muhtaseb and Ritter, 2003), it is known that the resorcinol is react with water to form hudroxymethyl derivatives $\left(-\mathrm{CH}_{2} \mathrm{OH}\right)$, and a condensation reaction of the hudroxymethyl derivatives with $\mathrm{F}$ to form methylene $\left(-\mathrm{CH}_{2}^{-}\right)$and methylene ether $\left(-\mathrm{CH}_{2} \mathrm{OCH}_{2}^{-}\right)$bridged compounds. At the same ambient aqueous condition, a sol-gel reaction between $\mathrm{M}$ and $\mathrm{F}$ were also observed (Raymundo-Pinero et al., 2002). In this work, we simultaneously put the M, R, F, and $\mathrm{PEO}_{76}-\mathrm{PPO}_{29}-\mathrm{PEO}_{76}$ in one react system, condensation reaction happens among the hydroxymethyl groups between $\mathrm{M}, \mathrm{R}$, and $\mathrm{F}$ to form small M-R-F clusters, which act as nucleation sites and incessantly increase to form a larger colloids. In this procedure, $\mathrm{PEO}_{76}-\mathrm{PPO}_{29}-\mathrm{PEO}_{76}$ micelles are coinstantaneous embedded within the growing colloids, which can stabilize the $\mathrm{M}-\mathrm{R}-\mathrm{F}$ three dimensional structure. Figure 1A shows the morphological and structural analysis of NC. It shows that the NC with a three dimensional structure comprises interconnected carbon spheres, and contain pores about one micron in size derived from the decomposition of $\mathrm{M}-\mathrm{F}$ and $\mathrm{PEO}_{76}-\mathrm{PPO}_{29}-\mathrm{PEO}_{76}(\mathrm{Xu}$ et al., 2012). The NC shows a foam-like microstructure with many internal interconnected channels, and this result is well agreed with other reports (Goldmints et al., 1997; Gutiérrez et al., 2009; Zhou et al., 2013). After activation at $950^{\circ} \mathrm{C}$ for
$10 \mathrm{~h}$ by $\mathrm{CO}_{2}$ (Figure 1B), the NMC also present a foam-like structure except that the carbon skeleton becomes smaller and the size of primary carbon spheres decreases (Lin and Ritter, 2000). This result is owing to $\mathrm{CO}_{2}$ etching effect, so the activation process lead to carbon loss. In addition, one would expect that amount of nano-pores are produced in the carbon skeleton by the $\mathrm{CO}_{2}$ etching effect, which could be further measured by $\mathrm{N}_{2}$ adsorption-desorption test in detail.

It is known that the $\mathrm{CO}_{2}$ activation can produce nanopores in carbon materials (Lin and Ritter, 2000; Chang et al., 2013) and cause different structure formation in nature, however, these features are hardly detected by SEM images (Figure 1B). So we further adopt HRTEM imaging, XRD patterns and Raman spectra to examine these changes of the prepared carbon materials. Figures 1C,D shows the HRTEM imaging of NC and NMC. It reveals the structure of NC and NMC is basically amorphous in nature. Specifically, some partly graphitized carbon structure can be observed from HRTEM imagines, and these structures have been reduced after $\mathrm{CO}_{2}$ activation. This phenomenon is coinciding with the XRD test results shown in Figure 1E. It shows two broad characteristic diffraction peaks at $2 \theta$ of $23.5^{\circ}(002)$ and $43.6^{\circ}$ (101), respectively, which can be regarded as a partly graphitized carbon. On the other hand, XRD pattern of the activated NMC displays a broader peak than the NC due to the decrease of the partly graphitized carbon structure by the $\mathrm{CO}_{2}$ etching. Moreover, Raman spectra of NC and NMC (Figure 1F) show two typically broad peaks of D band (around $1350 \mathrm{~cm}^{-1}$ ) and $\mathrm{G}$ band (around $1600 \mathrm{~cm}^{-1}$ ). Generally, The D band is related to disordered features of graphitic carbon, while the $G$ band is the typical characteristics of graphitic crystallites (Ji and Zhang, 2009). This result is corresponding to previous reports (Ferrari, 2007; Kicinski et al., 2013; Yi et al., 2017). The intensity ratio of $\mathrm{D}$ band and $\mathrm{G}$ band $\left(\mathrm{I}_{\mathrm{D}} / \mathrm{I}_{\mathrm{G}}\right)$ is the parameter usually used to analyze defective structures in carbonaceous materials. Calculated from the Figure $1 F$, the $I_{D} / I_{G}$ value of NMC and NC is 0.848 and 0.803 , respectively, the increased value of the NMC indicating that during the $\mathrm{CO}_{2}$ activation, the overall structure comprises graphite grains with an increasing amount of structural defects formed. The result well coincide with the HRTEM and XRD results which reveal the existence of amorphous carbon structure of NMC and NC.

\section{Textural Properties}

One expected that our resulted NMC is a multi-scaled carbon material including macropores $(>50 \mathrm{~nm})$, mesopores $(2-50 \mathrm{~nm})$, and micropores $(<2 \mathrm{~nm})$. The nitrogen adsorption/desorption isotherms can examine in detail these pore properties shown in Figure 2A. And the related pore size distributions profiles determined by the density functional theory (DFT) program are shown in Figure 2B. Corresponding pore properties are displayed in Table 1. Obviously, both NMC and AC have a higher absorbed amount than the NC, which reveals that the NMC and AC possess higher specific surface area and pore volume than NC (Table 1). In depth, all these isotherms of NC, NMC and AC possess adsorbed amount at low relative pressure which exhibit Type I characteristics behavior designating the existence of micropores. And the distinct increasing of adsorbed 

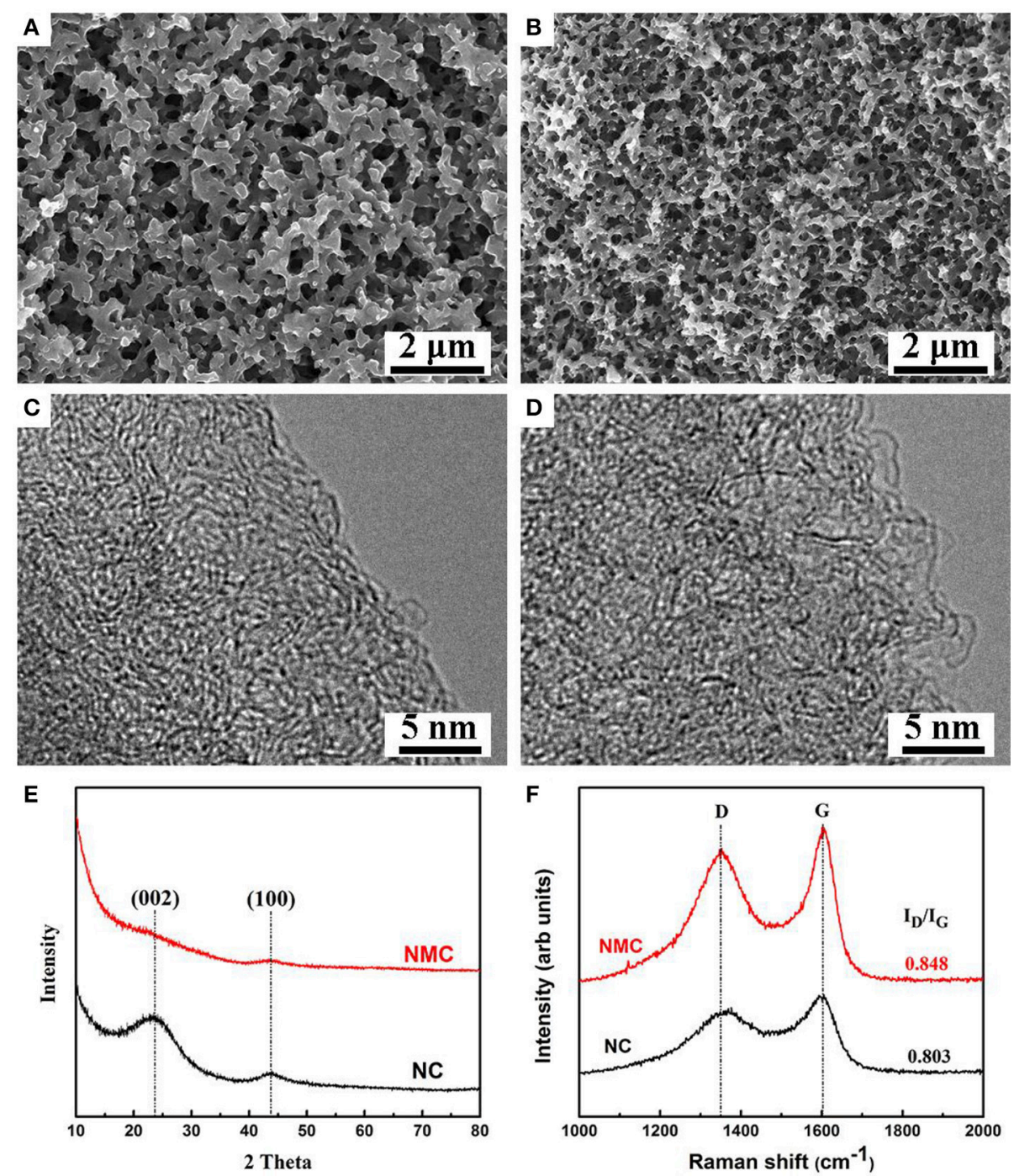

FIGURE 1 | SEM images (A,B), HRTEM images (C,D), XRD spectra (E), and Raman spectra (F) of the NC and NMC.

amount for the isotherms can be found, which reveals the increasing amounts of micropores. Another adsorption occurred at middle relative pressure display Type IV characteristics demonstrating the existence of mesopores (Long et al., 2008; Wang et al., 2008). Although, their adsorption curves are mostly consistent with their desorption curves, but the differences also exists at mid-/high-relative pressure. These kinds of isotherms are Type IV curves and Type H4 hysteresis loops, suggesting the existence of slit-shaped pores. This result can be further confirmed by the pore size distributions displayed in Figure 2B. The additional $\mathrm{CO}_{2}$ activation process bring abundant $2 \mathrm{~nm}$-pores of the NMC, and it possess a high BET specific surface area of $3,170 \mathrm{~m}^{2} \mathrm{~g}^{-1}$ and a total pore volume of $1.880 \mathrm{~cm}^{3} \mathrm{~g}^{-1}$ shown in Table 1. In summary, NMC possessing high surface area and multi-scale porous structure was successfully prepared. More mesopores exist in NMC (Figure 2B) are beneficial to electrochemical performance in the high-voltage aqueous supercapacitors (Hasegawa et al., 2016).

\section{XPS Study}

XPS was employed to evaluate the surface chemistry in NC and NMC. As shown in Figure S1, three elements (C, N, O) exist in both NC and NMC. The total nitrogen heteroatom doping content was 4.9 at.\% in NC and decreased to 3.2 at.\% in NMC. The decrease of nitrogen content is owing to its higher reaction activities than that of carbon during high temperature activation process (Liu et al., 2012). The highresolution spectrum of $\mathrm{C} 1 \mathrm{~s}$ and $\mathrm{N} 1 \mathrm{~s}$ are shown in Figure 3. The C1s spectrum of NC and NMC can be fitted to five peaks show in Figures 3A,C, respectively. The peak located around $284.4,285.3,286.5$, and $288,289.3 \mathrm{eV}$ are attribute to the $\mathrm{C}-\mathrm{C}$ or $\mathrm{C}=\mathrm{C}$ band $(\mathrm{C}-1), \mathrm{sp}^{3}$-like defects $(\mathrm{C}-2), \mathrm{C}-\mathrm{N}$ or $\mathrm{C}-\mathrm{O}$ species (C-3), $\mathrm{C}=\mathrm{O}$ band (C-4), and $\pi-\pi^{*}$ band (C-5), respectively 

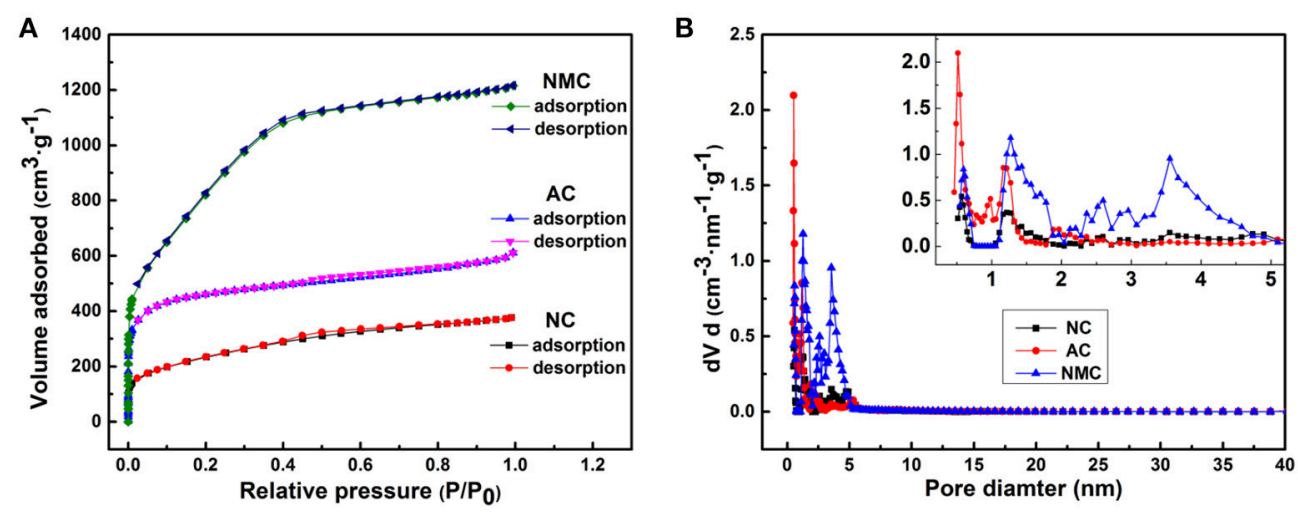

FIGURE 2 | Nitrogen adsorption/desorption isotherms (A) and pore size distribution (B) of the NC, AC, and NMC.

TABLE 1 | Corresponding pore parameters of the NC, AC, and NMC.

\begin{tabular}{lccc}
\hline & $\begin{array}{c}\text { BET specific surface area } \\
\left(\mathbf{m}^{\mathbf{2}} \mathbf{g}^{-\mathbf{1}} \mathbf{)}\right.\end{array}$ & $\begin{array}{c}\text { Average pore size } \\
\mathbf{( n m )}\end{array}$ & $\begin{array}{c}\text { Total pore volume } \\
\left(\mathbf{c m}^{\mathbf{3}} \mathbf{g}^{-\mathbf{1}} \mathbf{)}\right.\end{array}$ \\
\hline $\mathrm{NC}$ & 840 & 2.77 & 0.582 \\
$\mathrm{AC}$ & 1724 & 2.20 & 0.948 \\
$\mathrm{NMC}$ & 3170 & 2.37 & 1.880 \\
\hline
\end{tabular}

(Hernández-Fernández et al., 2010; Lim et al., 2012). The analysis results of C1s spectrum could verify the amorphous structure of the NC and NMC Analysis high-resolution spectrum of N1s spectra (Figures 3B,D), four peaks around 398, 400.5, 401.6, and $402.8 \mathrm{eV}$, which can be assigned to pyridinic- $\mathrm{N}(\mathrm{N}-6)$, pyrrolic-N (N-5), quaternary-N (N-Q), and pyridine-N-oxide $(\mathrm{N}-\mathrm{X})$, respectively (Raymundo-Pinero et al., 2002; Long et al., 2008; Braghiroli et al., 2012; Horikawa et al., 2012). Figure 4 shows the different types of nitrogen atoms in a carbon matrix. And the corresponding contents of nitrogen in NC and NMC are shown in Table 2. Obviously, compared with the NMC and $\mathrm{NC}$, the nitrogen chemical state is not change even after $\mathrm{CO}_{2}$ activation process. These $\mathrm{N}$-containing functional groups should make both NC and NMC more electrochemically active, indicating it has excellent capacitance properties (Geng et al., 2011; Lim et al., 2012). To sum up, this change of surface chemical compositions is good for electrochemical properties of NMC.

\section{Electrochemical Results}

The multi-scale porous features of the electrode is expected to facilitate the rapid diffusion of electrolyte ion within the electrode (Qin et al., 2016). To investigate the kinetic stability of NMC in high voltage aqueous SCs, the electrochemical performances were evaluated by using two- and three-electrode cells in $20 \mathrm{~m}$ LiTFSI aqueous solution. Figure 5A displays the typical CV curves of the NMC symmetric SCs at the same scan rate of $5 \mathrm{mV} \mathrm{s}^{-1}$ in a different operating voltage window from 1 to $2.4 \mathrm{~V}$ with stepwise shifting voltage of $0.2 \mathrm{~V}$. It is obvious that LiTFSI-based aqueous electrolytes possess a high stability comparing with organic electrolyte (Zhao et al., 2016), revealing the high adaptability in high voltage cell. Furthermore, the CV profiles of the NMC electrode are nearly rectangle in shape and no obvious redox peaks are detected, which is a very common feature of electrochemical double layer (EDL) capacitor (the schematic of symmetric two-electrode configuration shown in Figure S3). Moreover, it is well known that the charge which is stored within the capacitor may be determined by integrating the CV. The increased area under the curve with increasing scan potential range is clearly observed, indicating an increasing capacitance and high voltage capability of the electrode. This result is consistent with the GCD measurements shown in Figure 5B. The GCD curves of the NMC performed at current density of $0.1 \mathrm{~A} \mathrm{~g}^{-1}$ in a different operating voltage window from 1 to $2.4 \mathrm{~V}$ with stepwise shifting voltage of $0.2 \mathrm{~V}$. It can be observed all the GCD curves display a similar linear change of the voltage. With the increasing charge/discharge voltage, the nearly symmetric relationship between the potential vs. time was also observed, suggesting the desired fast charging, and discharging property of the NMC. Slight internal resistance (IR) drops of NMC electrode are observed for any of the curves, which indicate high conductivity of our electrode materials. Calculated from the GCD curves (Figure 5B), the single electrode specific capacitance $\left(\mathrm{C}_{\mathrm{s}}\right)$ increase from 120 to $160 \mathrm{~F} \mathrm{~g}^{-1}$ while the operating voltage increase from 1 to $2.4 \mathrm{~V}$. With the working voltage increased, more sufficient surface area can be used to form EDL in the NMC electrode, which mainly attributes to higher Cs. When the symmetric capacitor operate at a high voltage of $2.4 \mathrm{~V}$ in $20 \mathrm{~m}$ LiTFSI electrolyte, the real potential of the positive and negative electrodes was separately determined by incorporating a SCE reference electrode (Figure 5C). The long term cycling stability applying high voltage of $2.4 \mathrm{~V}$ is the critical factor to appraise the practical applications of electrodes. In order to explore this, the cycle stability of NMC was further investigated by repeating the GCD test at a current density of $1 \mathrm{~A} \mathrm{~g}^{-1}$ for 10,000 cycles in $20 \mathrm{~m}$ LiTFSI electrolyte as shown in Figure 5D. It was observed that the initial capacitance of NMC electrode is $\sim 150 \mathrm{~F} \mathrm{~g}^{-1}$, and gradually decrease to $120 \mathrm{~F} \mathrm{~g}^{-1}$ during the first 1,000 cycles, but nearly no obvious capacitance decrease during the next thousands cycles. Impressively, even after 10,000 continuous charge/discharge cycles, the NMC electrode retains 

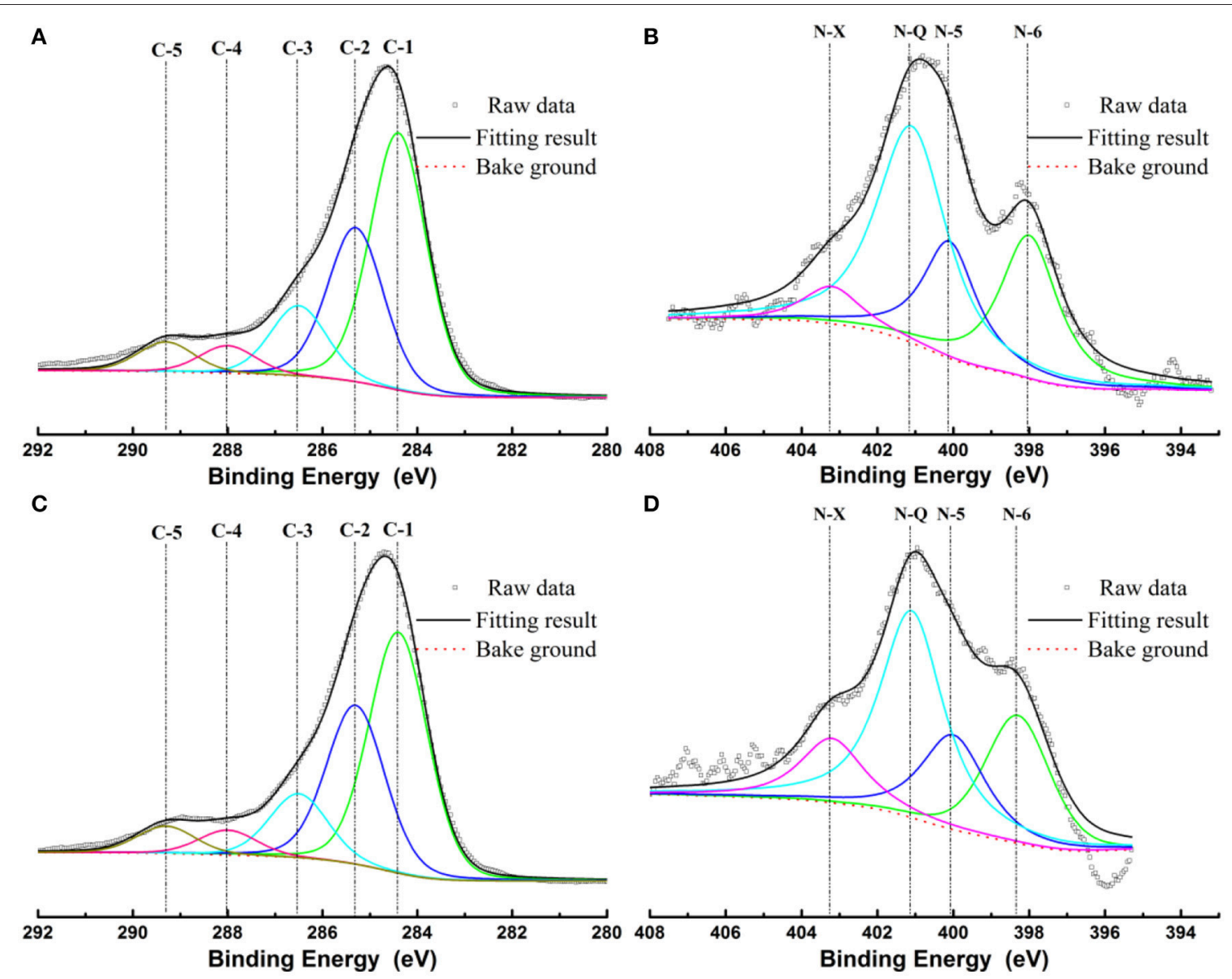

FIGURE 3 | XPS spectra C1s (A,C) and N1s (B,D) of the NC and NMC, respectively.

about $80 \%$ of the initial capacitance and exhibits excel lent cycle stability. In contrast, the specific capacitance of AC electrode decreases rapidly from 118 to $86 \mathrm{~F} \mathrm{~g}^{-1}$ during the first 300 cycles, and then gradually decreases to $72 \mathrm{~F} \mathrm{~g}^{-1}$ (only $61 \%$ of the initial capacitance is retained) after 10,000 cycles. Figure 5E shows the CV profiles of NMC symmetric SCs at a scan rate of $5,10,20,50$, and $100 \mathrm{mV} \mathrm{s}^{-1}$, respectively. The rectangularshape of CV profile is moderately distorted with the increasing scanning rate, which is attributed to the difficult diffusion of ions from electrolyte to the porous structure at high scan rate. In addition, the capacitance decrease with the increasing scan rate, which is consistent with the GCD tests at different current density (Figure 5F). The calculated $\mathrm{C}_{\mathrm{s}}$ of the NMC in $2.4 \mathrm{~V}$ is $167,160,155,146,124$, and $112 \mathrm{~F} \mathrm{~g}^{-1}$ at current densities of $0.1,0.2,0.5,1,2$, and $5 \mathrm{~A} \mathrm{~g}^{-1}$, respectively, demonstrating that the specific capacitance decrease with increasing current density. Furthermore, the retain of capacitance is about $74 \%$ when the current density increase from 0.1 to $5 \mathrm{~A} \mathrm{~g}^{-1}$ in $2.4 \mathrm{~V}$.

To further discuss the kinetic stability of the NMC under high voltage. The $\mathrm{CV}$ and GCD tests for NMC, AC and AC from 1 to $2.4 \mathrm{~V}$ were investigated respectively, as shown in Figure 6

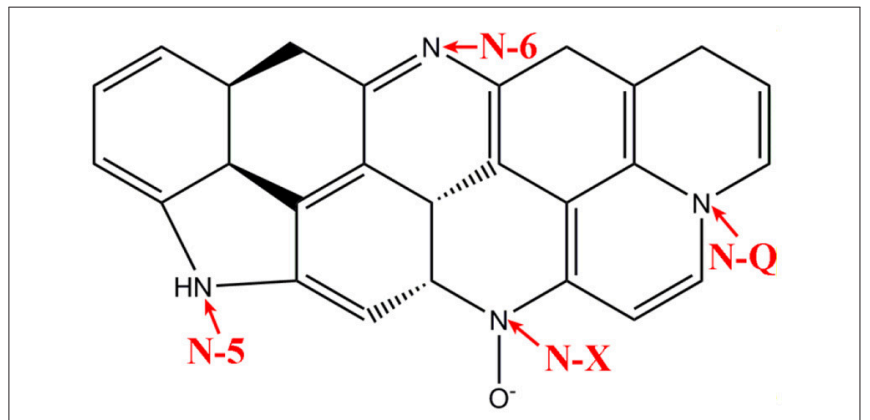

FIGURE 4 | Schematic illustration of different types of nitrogen forms in NMC.

and Figure S2. The observed integrated area increases with NC $<\mathrm{AC}<\mathrm{NMC}$, indicating that the proper multi-scale pore of NMC is beneficial for the specific capacitance. The Cs of NC, $\mathrm{AC}$, and $\mathrm{NMC}$ is 58,94 , and $120 \mathrm{~F} \mathrm{~g}^{-1}$ at the operating potential of $1 \mathrm{~V}$, respectively. Whereas, when the operating potential reaches up to $2.4 \mathrm{~V}$, the $\mathrm{Cs}$ increases to 73,114 , and $160 \mathrm{~F}$ $\mathrm{g}^{-1}$, respectively. The increased Cs is due to the achievement 
of optimal synergistic effects of multi-scale porous structure and proper nitrogen contents (Zhang et al., 2016). The results obtained here are also in consistent with the SEM morphologies and $\mathrm{N}_{2}$ adsorption-desorption test result, suggesting the NM $\mathrm{C}$ morphology provides good channels fascinating fast charge

TABLE 2 | Nitrogen forms of the NC and NMC.

\begin{tabular}{lcccc}
\hline Sample & \multicolumn{4}{c}{ Nitrogen forms at. \% } \\
\cline { 2 - 5 } & $\mathbf{N}-6$ & $\mathbf{N}-\mathbf{5}$ & $\mathbf{N}-\mathbf{Q}$ & $\mathbf{N}-\mathbf{X}$ \\
\hline NC & 26.1 & 20.7 & 46.5 & 6.7 \\
NMC & 22.8 & 19.4 & 44.1 & 13.7
\end{tabular}

intercalation/deintercalation process. As shown in Figure 6C, Nyquist plots for all these three samples consist of a semicircle at high frequency value followed by a slant at low frequency value. The semicircle is ascribed to the charges transfer processes between the electrode and the electrolyte. It is clear that the NC and NMC have the smaller radius of semicircle meaning the smaller charge transfer impedance, which because of the presence of nitrogen provides good electronic conductivity for NC and NMC (Liu et al., 2015). In addition, the slant form Warburg impedance indicates the electrolyte ion diffusion into the electrode. And the AC electrode shows a higher Warburg angel meaning lower ion diffusion which is attributed to the AC have a large number of micropores but lack of microchannels for the fast ion diffusion (Díez et al., 2017). Figure 6D

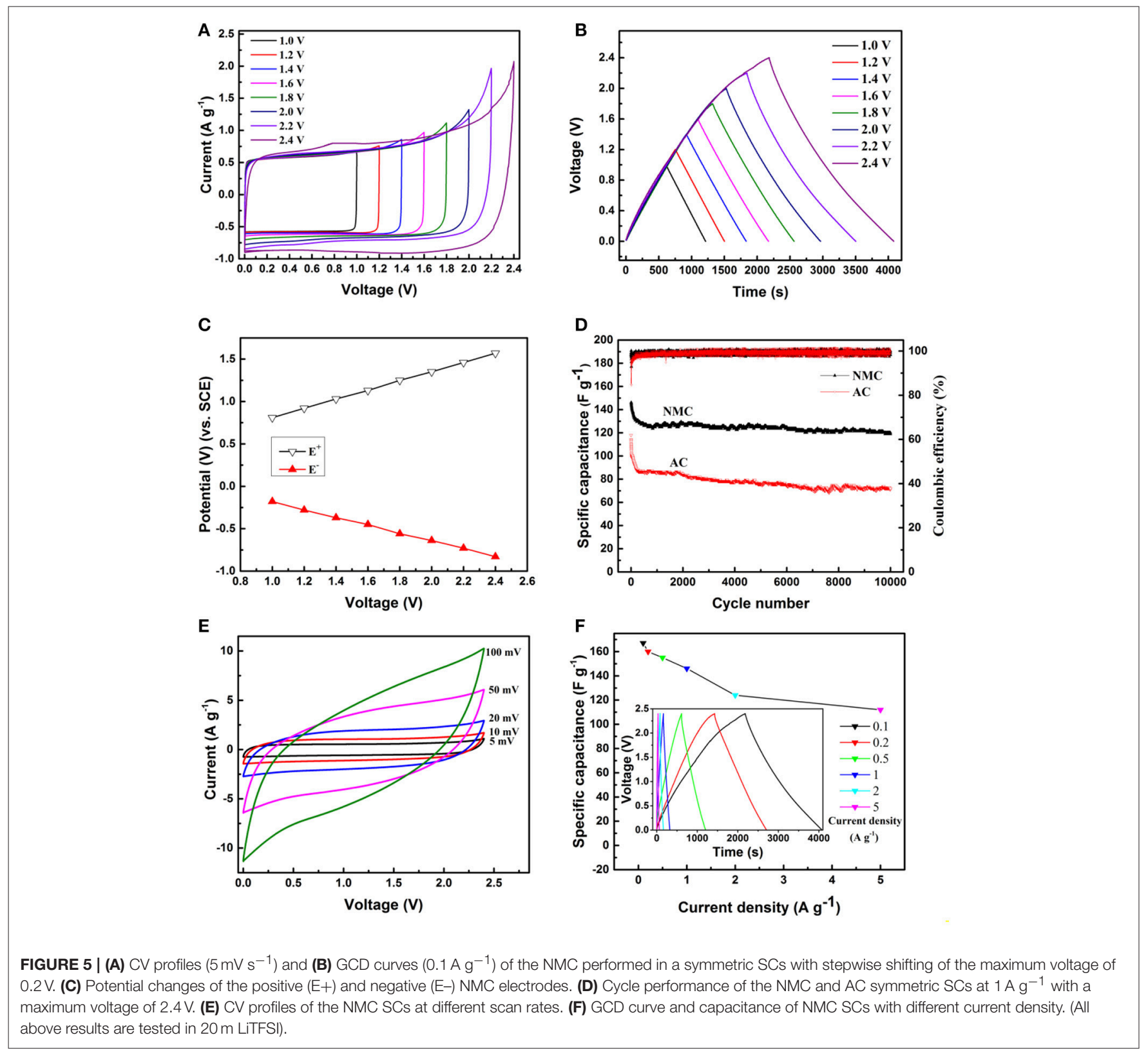



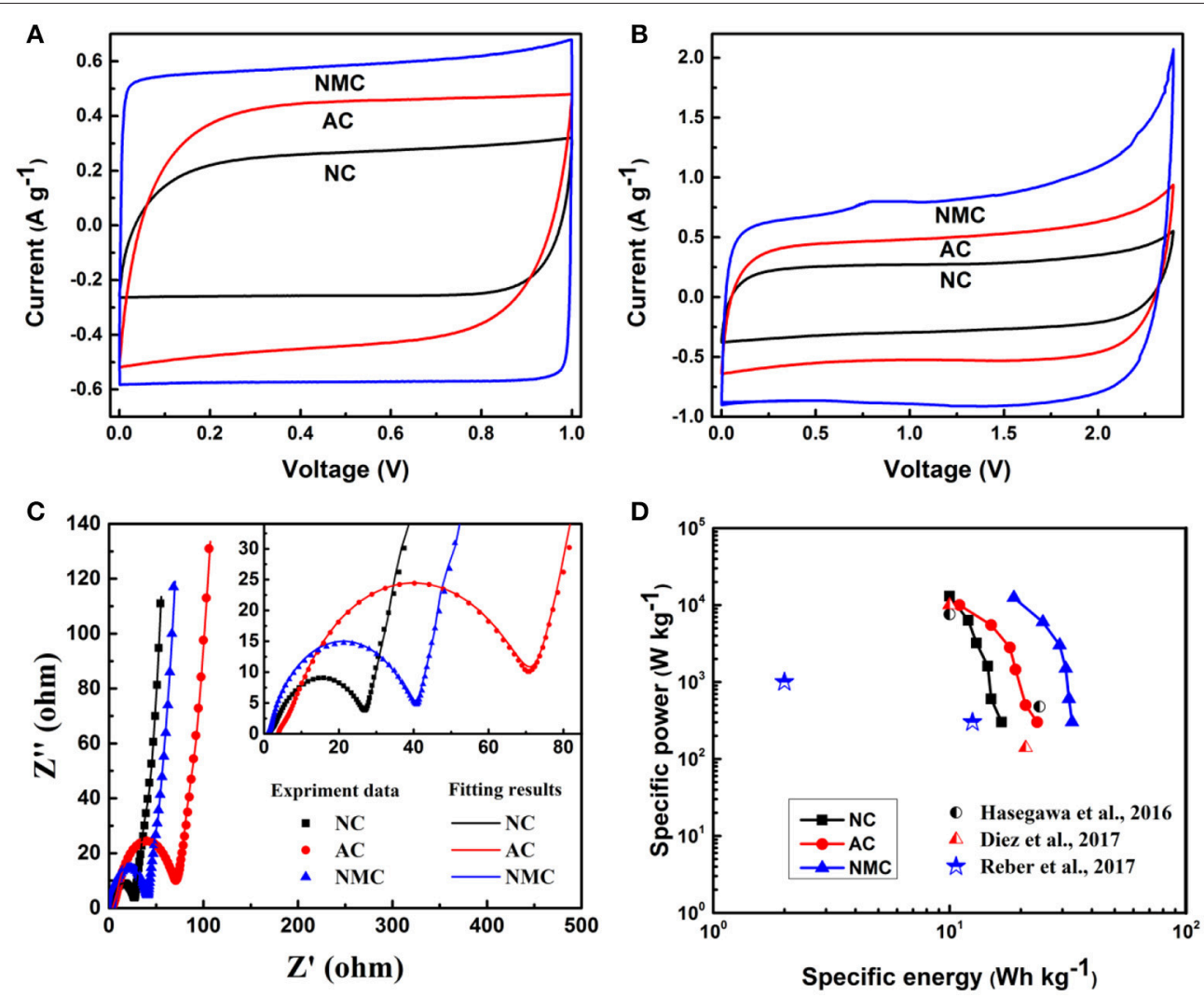

FIGURE 6 | CV profiles of the NC, AC, and NMC in $20 \mathrm{~m}$ LiTFSI performed in a symmetric capacitor at $5 \mathrm{mV} \mathrm{s}^{-1}$ with the different maximum operating voltage of $1 \mathrm{~V}$ (A) and 2.4 V (B). (C) Nyquist impedance spectra of the NC, AC, and NMC. (D) The Ragone plots of the NC, AC, NMC, and relative previous works.

shows the relationship between energy density and power density of the different electrode materials performed in symmetric capacitor. The specific energy and power were derived from GCD tests at voltage of $2.4 \mathrm{~V}$ evaluated using the Equations (1) and (2). It is clear that the symmetric capacitor based on NMC electrodes materials delivered the highest overall energy density of $33 \mathrm{Wh} \mathrm{kg}^{-1}$ at $0.3 \mathrm{~kW} \mathrm{~kg}^{-1}$. This result is higher than that of previous homologous works (Gambou-Bosca and Bélanger, 2016; Hasegawa et al., 2016; Díez et al., 2017). Moreover, it is worth noting that the NMC can provide $18 \mathrm{Wh} \mathrm{kg}^{-1}$ of specific energy when the power density reaches up to $12 \mathrm{~kW}$ $\mathrm{kg}^{-1}$. Compared with previous literatures (Hasegawa et al., 2016; Díez et al., 2017; Reber et al., 2017), our works exhibit better performance (Figure 6D) in both energy density and power density.

\section{CONCLUSIONS}

$\mathrm{N}$-doped multi-scale porous carbon has been synthesized by a simple sol-gel method and successfully applied in high voltage aqueous electrolyte up to $2.4 \mathrm{~V}$. Morphological and textural characterizations show that the NMC exhibit three dimensional porous channels with a high specific surface area of $3,170 \mathrm{~m}^{2} \mathrm{~g}^{-1}$, large pore volume of $1.880 \mathrm{~cm}^{3}$ $\mathrm{g}^{-1}$, multi-scale pores and suitable contents of nitrogen functional groups. Electrochemical performances of NMC was observed for a symmetric electrodes system offering good capacitive performance, possessing energy density of $33 \mathrm{Wh} \mathrm{kg}^{-1}$ at $0.3 \mathrm{~kW} \mathrm{~kg}^{-1}$ in $20 \mathrm{~m}$ LiTFSI electrolyte and stable cycle performance (about 73\%) over 10,000 charge-discharge cycles in high voltage of $2.4 \mathrm{~V}$. The high performance characteristics of NMC contribute to the synergistic effect benefiting ion diffusion, transport and adsorption, and charge accumulation. This work demonstrated this nitrogen-doped multi-scale porous carbon is a promising electrode material for high-voltage aqueous electrolyte applications.

\section{AUTHOR CONTRIBUTIONS}

YT developed the concept. $\mathrm{XL}$ and $\mathrm{CW}$ designed the experiments. XL, RM, and LY conducted the preparation of materials. XL, FY, and RM built the cells and carried out the performance characterizations. $\mathrm{ZF}$ and $\mathrm{CW}$ supervised the research. XL and FY co-wrote the manuscript. All authors discussed the results and commented on the manuscript. 


\section{FUNDING}

This study was financially supported by the Research Program of Sichuan province (Grant No. 2016GZ0235).

\section{ACKNOWLEDGMENTS}

We are grateful to Xi Yang, Minglong Zhong, Qi Yang, Yong Zeng, and Jia Li (Science and Technology on plasma physics

\section{REFERENCES}

Al-Muhtaseb, S. A., and Ritter, J. A. (2003). Preparation and properties of resorcinol-formaldehyde organic and carbon gels. Adv. Mater. 15, 101-114. doi: 10.1002/adma.200390020

Braghiroli, F. L., Fierro, V., Izquierdo, M. T., Parmentier, J., Pizzi, A., and Celzard, A. (2012). Nitrogen-doped carbon materials produced from hydrothermally treated tannin. Carbon 50, 5411-5420. doi: 10.1016/j.carbon.2012. 07.027

Chang, Y.-M., Wu, C.-Y., and Wu, P.-W. (2013). Synthesis of large surface area carbon xerogels for electrochemical double layer capacitors. J. Power Sources 223, 147-154. doi: 10.1016/j.jpowsour.2012.09.066

Ci, S., Wen, Z., Chen, J., and He, Z. (2012). Decorating anode with bamboolike nitrogen-doped carbon nanotubes for microbial fuel cells. Electrochem. Commun. 14, 71-74. doi: 10.1016/j.elecom.2011.11.006

Dai, S., Zhao, B., Qu, C., Chen, D., Dang, D., Song, B., et al. (2017). Controlled synthesis of three-phase $\mathrm{Ni}$ x S y /rGO nanoflake electrodes for hybrid supercapacitors with highenergy and power density. Nano Energy 33, 522-531. doi: 10.1016/j.nanoen.2017.01.056

Díez, N., Mysyk, R., Zhang, W., Goikolea, E., and Carriazo, D. (2017). One-pot synthesis of highly activated carbons from melamine and terephthalaldehyde as electrodes for high energy aqueous supercapacitors. J. Mater. Chem. A 5, 14619-14629. doi: 10.1039/c7ta01424d

Fang, X., Zang, J., Wang, X., Zheng, M.-,s., and Zheng, N. (2013). A multiple coating route to hollow carbon spheres with foam-like shells and their applications in supercapacitor and confined catalysis. J. Mater. Chem. A 2, 6191-6197. doi: 10.1039/c3ta14881e

Ferrari, A. C. (2007). Raman spectroscopy of graphene and graphite: Disorder, electron-phonon coupling, doping and nonadiabatic effects. Solid State Commun. 143, 47-57. doi: 10.1016/j.ssc.2007.03.052

Fu, W., Zhao, E., Ren, X., Magasinski, A., and Yushin, G. (2018). Hierarchical Fabric Decorated with Carbon Nanowire/Metal Oxide Nanocomposites for 1.6 V Wearable Aqueous Supercapacitors. Adv. Energy Mater. 2018:1703454. doi: 10.1002/aenm.201703454

Gambou-Bosca, A., and Bélanger, D. (2016). Electrochemical characterization of $\mathrm{MnO} 2$-based composite in the presence of salt-in-water and water-in-salt electrolytes as electrode for electrochemical capacitors. J. Power Sources 326, 595-603. doi: 10.1016/j.jpowsour.2016.04.088

Geng, D., Chen, Y., Chen, Y., Li, Y., Li, R., Sun, X., et al. (2011). High oxygenreduction activity and durability of nitrogen-doped graphene. Energy Environ. Sci. 4, 760-768. doi: 10.1039/c0ee00326c

Goldmints, I., Holzwarth, J. F., Smith, K. A., and Hatton, T. A. (1997). Micellar dynamics in aqueous solutions of PEO-PPO-PEO block copolymers. Langmuir 13, 6130-6134. doi: 10.1021/la970534m

Gutiérrez, M. C., Picó, F., Rubio, F., Manuel Amarilla, J., Javier Palomares, F., Ferrer, M. L., et al. (2009). PPO15-PEO22-PPO15 block copolymer assisted synthesis of monolithic macro- and microporous carbon aerogels exhibiting high conductivity and remarkable capacitance. J. Mater. Chem. 19, 1236-1240. doi: $10.1039 / \mathrm{b} 820412 \mathrm{~h}$

Hasegawa, G., Kanamori, K., Kiyomura, T., Kurata, H., Abe, T., and Nakanishi, K. (2016). Hierarchically porous carbon monoliths comprising ordered mesoporous nanorod assemblies for high-voltage aqueous supercapacitors. Chem. Mater. 28, 3944-3950. doi: 10.1021/acs.chemmater. $6 \mathrm{~b} 01261$
Laboratory, Research Centre of Laser Fusion, China Academy of Engineering physics, Mianyang, China) for their valuable discussions and assistance in measurements.

\section{SUPPLEMENTARY MATERIAL}

The Supplementary Material for this article can be found online at: https://www.frontiersin.org/articles/10.3389/fchem. 2018.00475/full\#supplementary-material
Hernández-Fernández, P., Montiel, M., Ocón, P., de la Fuente, J. L. G. García-Rodríguez, S., Rojas, S., et al. (2010). Functionalization of multiwalled carbon nanotubes and application as supports for electrocatalysts in proton-exchange membrane fuel cell. Appl. Catalysis B Environ. 99, 343-352. doi: 10.1016/j.apcatb.2010.07.005

Horikawa, T., Sakao, N., Sekida, T., Hayashi, J. I., Do, D. D., and Katoh, M. (2012). Preparation of nitrogen-doped porous carbon by ammonia gas treatment and the effects of $\mathrm{N}$-doping on water adsorption. Carbon 50, 1833-1842. doi: 10.1016/j.carbon.2011.12.033

Huang, C. H., Zhang, Q., Chou, T. C., Chen, C. M., Su, D. S., and Doong, R. A. (2012). Three-dimensional hierarchically ordered porous carbons with partially graphitic nanostructures for electrochemical capacitive energy storage. ChemSusChem 5, 563-571. doi: 10.1002/cssc.201100618

Hwang, J. Y., El-Kady, M. F., Li, M., Lin, C. W., Kowal, M., Han, X., et al. (2017). Boosting the capacitance and voltage of aqueous supercapacitors via redox charge contribution from both electrode and electrolyte. Nano Today 15:009. doi: 10.1016/j.nantod.2017.06.009

Ji, L., and Zhang, X. (2009). Fabrication of porous carbon nanofibers and their application as anode materials for rechargeable lithium-ion batteries. Nanotechnology 20:155705. doi: 10.1088/0957-4484/20/15/155705

Jia, J., Liu, X., Mi, R., Liu, N., Xiong, Z., Yuan, L., et al. (2018). Selfassembled pancake-like hexagonal tungsten oxide with ordered mesopores for supercapacitors. J. Mater. Chem. A 6, 15330-15339 doi: 10.1039/C8TA05292A

Kicinski, W., Norek, M., and Bystrzejewski, M. (2013). Monolithic porous graphitic carbons obtained through catalytic graphitization of carbon xerogels. J. Phys. Chem. Solids 74, 101-109. doi: 10.1016/j.jpcs.2012.08.007

Kühnel, R.-S., and Balducci, A. (2014). Comparison of the anodic behavior of aluminum current collectors in imide-based ionic liquids and consequences on the stability of high voltage supercapacitors. J. Power Sources 249, 163-171. doi: 10.1016/j.jpowsour.2013.10.072

Lim, J. W., Jeong, E., Min, J. J., Sang, I. L., and Lee, Y. S. (2012). Effect of simultaneous etching and N-doping on the surface and electrochemical properties of AC. J. Ind. Eng. Chem. 18, 116-122. doi: 10.1016/j.jiec.2011.11.074

Lin, C., and Ritter, J. A. (2000). Carbonization and activation of sol-gel derived carbon xerogels. Carbon 38, 849-861. doi: 10.1016/S0008-6223(99)00189-X

Liu, H., Zhang, Y., Li, R., Sun, X., and Abou-Rachid, H. (2012). Thermal and chemical durability of nitrogen-doped carbon nanotubes. J. Nanopart. Res. 14, 1-8. doi: 10.1007/s11051-012-1016-0

Liu, X., Li, S., Mi, R., Mei, J., Liu, L.-M., Cao, L., et al. (2015). Porous structure design of carbon xerogels for advanced supercapacitor. Appl. Energ. 153, 32-40. doi: 10.1016/j.apenergy.2015.01.141

Liu, X., Sheng, G., Zhong, M., and Zhou, X. (2018a). Dispersed and size-selected WO 3 nanoparticles in carbon aerogel for supercapacitor applications. Mater. Design. 141, 220-229. doi: 10.1016/j.matdes.2017.12.038

Liu, X., Sheng, G., Zhong, M., and Zhou, X. (2018b). Hybrid nanowires and nanoparticles of WO3 in a carbon aerogel for supercapacitor applications. Nanoscale 10, 4209-4217. doi: 10.1039/c7nr07191d

Long, D., Zhang, J., Yang, J., Hu, Z., Cheng, G., Liu, X., et al. (2008). Chemical state of nitrogen in carbon aerogels issued from phenol-melamine-formaldehyde gels. Carbon 46, 1259-1262. doi: 10.1016/j.carbon.2008.04.022

Qin, K., Liu, E., Li, J., Kang, J., Shi, C., He, C., et al. (2016). Free-standing 3D nanoporous duct-like and hierarchical nanoporous graphene films for micronlevel flexible solid-state asymmetric supercapacitors. Adv. Energy Mater. 6:1600755. doi: 10.1002/aenm.201600755 
Qu, C., Zhang, L., Meng, W., Liang, Z., Zhu, B., Dang, D., et al. (2018). MOF-Derived $\alpha$-NiS nanorods on graphene as an electrode for high-energydensity supercapacitors. J. Mater. Chem. A 6, 4003-4012 doi: 10.1039/C7TA $11100 \mathrm{~B}$

Raymundo-Pinero, E., Cazorla-Amoros, D., Linares-Solano, A., Wild, U., and Schlögl, R. (2002). Structural characterization of N-containing activated carbon fibers prepared from a low softening point petroleum pitch and a melamine resin. Carbon 40, 597-608. doi: 10.1016/S0008-6223(01)00155-5

Reber, D., Kühnel, R.-S., and Battaglia, C. (2017). High-voltage aqueous supercapacitors based on NaTFSI. Sustain. Energy Fuels 1, 2155-2161. doi: $10.1039 / \mathrm{c} 7 \mathrm{se} 00423 \mathrm{k}$

Suo, L., Borodin, O., Gao, T., Olguin, M., Ho, J., Fan, X., et al. (2015). "Water-insalt” electrolyte enables high-voltage aqueous lithium-ion chemistries. Science 350:938. doi: 10.1126/science.aab1595

Wang, X., Liang, C., and Dai, S. (2008). Facile synthesis of ordered mesoporous carbons with high thermal stability by self-assembly of resorcinolformaldehyde and block copolymers under highly acidic conditions. Langmuir 24, 7500-7505. doi: 10.1021/la800529v

Wen, Z., Wang, X., Mao, S., Bo, Z., Kim, H., Cui, S., et al. (2012). Crumpled nitrogen-doped graphene nanosheets with ultrahigh pore volume for high-performance supercapacitor. Adv. Mater. 24, 5610-5616. doi: 10.1002/adma.201201920

Xu, J., Wang, A., and Zhang, T. (2012). A two-step synthesis of ordered mesoporous resorcinol-formaldehyde polymer and carbon. Carbon 50, 1807-1816. doi: 10.1016/j.carbon.2011.12.028

Yang, J., Hu, J., Zhu, M., Zhao, Y., Chen, H., and Pan, F. (2017). Ultrahigh surface area meso/microporous carbon formed with self-template for high-voltage aqueous supercapacitors. J. Power Sources 365, 362-371. doi: 10.1016/j.jpowsour.2017.08.114

Yi, Z., Xu, X., Kang, X., Zhao, Y., Zhang, S., Yao, W., et al. (2017). Fabrication of well-aligned $\mathrm{ZnO} @ \mathrm{Ag}$ nanorod arrays with effective charge transfer for surface-enhanced Raman scattering. Surf. Coat. Tech. 324, 257-263. doi: 10.1016/j.surfcoat.2017.05.084

Yu, M., Lu, Y., Zheng, H., and Lu, X. (2017). New Insights into the Operating Voltage of Aqueous Supercapacitors. Chem-eur. J. 24, 3639-3649. doi: 10.1002/chem.201704420

Zao, Y., Gao, N., Luo, J., Kang, X., Yao, W., Zhang, W., et al. (2016). Ordered array of Ag semishells on different diameter monolayer polystyrene colloidal crystals: an ultrasensitive and reproducible SERS substrate. Sci. Rep. 6:32314. doi: 10.1038/srep32314

Zeng, Y., Chen, X. F., Yi, Z., Yi, Y., and Xu, X. (2018a). Fabrication of $\mathrm{p}$-n heterostructure $\mathrm{ZnO} / \mathrm{Si}$ moth-eye structures: antireflection, enhanced charge separation and photocatalytic properties. Appl. Surf. Sci. 441, 40-48. doi: 10.1016/j.apsusc.2018.02.002

Zeng, Y., Fan, X., Chen, J., He, S., Yi, Z., Ye, X., et al. (2018b). Preparation of composite micro/nano structure on the silicon surface by reactive ion etching: enhanced anti-reflective and hydrophobic properties. Superlattice. Microst 117, 144-154. doi: 10.1016/j.spmi.2018.03.035
Zhang, J., Zhou, J., Wang, D., Hou, L., and Gao, F. (2016). Nitrogen and sulfur codoped porous carbon microsphere: a high performance electrode in supercapacitor. Electrochim. Acta 191, 933-939. doi: 10.1016/j.electacta.2016.01.150

Zhang, Q., Chen, H., Luo, L., Zhao, B., Luo, H., Han, X., et al. (2018a). Harnessing the concurrent reaction dynamics in active Si and Ge to achieve high performance of lithium-ion batteries. Energy Environ. Sci. 11, 669-681 doi: 10.1039/C8EE00239H

Zhang, Q., Liu, Z., Zhao, B., Cheng, Y., Zhang, L., Wu, H. H., et al. (2018b). Design and understanding of dendritic mixed-metal hydroxide nanosheets@Ndoped carbon nanotube array electrode for high-performance asymmetric supercapacitors. Energy Storage Mater. doi: 10.1016/j.ensm.2018.06.026.

Zhao, B., Zhang, L., Zhang, Q., Chen, D., Cheng, Y., Deng, X., et al. (2017). Rational design of nickel hydroxide-based nanocrystals on graphene for ultrafast energy storage. Adv. Energy Mater. 8:1702247. doi: 10.1002/aenm.201702247

Zhao, Y.-Q., Lu, M., Tao, P.-Y., Zhang, Y.-J., Gong, X.-T., Yang, Z., et al. (2016). Hierarchically porous and heteroatom doped carbon derived from tobacco rods for supercapacitors. J. Power Sources 307, 391-400. doi: 10.1016/j.jpowsour.2016.01.020

Zhong, C., Deng, Y., Hu, W., Qiao, J., Zhang, L., and Zhang, J. (2015). A review of electrolyte materials and compositions for electrochemical supercapacitors. Chem. Soc. Rev. 44, 7484-7539. doi: 10.1039/c5cs00303b

Zhong, H., Zhang, H., Liu, S., Deng, C., and Wang, M. (2013). Nitrogen-enriched carbon from melamine resins with superior oxygen reduction reaction activity. ChemSusChem 6, 807-812. doi: 10.1002/cssc.201200919

Zhou, H., Xu, S., Su, H., Wang, M., Qiao, W., Ling, L., et al. (2013). Facile preparation and ultra-microporous structure of melamine-resorcinolformaldehyde polymeric microspheres. Chem. Commun. 49, 3763-3765. doi: 10.1039/C3CC41109E

Zhu, J., Xu, D., Qian, W., Zhang, J., and Yan, F. (2016). Heteroatom-containing porous carbons derived from ionic liquid-doped alkali organic salts for supercapacitors. Small 12, 1935-1944. doi: 10.1002/smll.201600010

Zuo, W., Xie, C., Xu, P., Li, Y., and Liu, J. (2017). A Novel phasetransformation activation process toward Ni-Mn-O nanoprism arrays for $2.4 \mathrm{~V}$ ultrahigh-voltage aqueous supercapacitors. Adv. Mater. 29:1703463. doi: 10.1002/adma.201703463

Conflict of Interest Statement: The authors declare that the research was conducted in the absence of any commercial or financial relationships that could be construed as a potential conflict of interest.

Copyright (c) $2018 \mathrm{Liu}, \mathrm{Mi}$, Yuan, Yang, Fu, Wang and Tang. This is an open-access article distributed under the terms of the Creative Commons Attribution License (CC $B Y)$. The use, distribution or reproduction in other forums is permitted, provided the original author(s) and the copyright owner(s) are credited and that the original publication in this journal is cited, in accordance with accepted academic practice. No use, distribution or reproduction is permitted which does not comply with these terms. 